\title{
Early Detection Of Glaucoma Disease In Retinal Fundus Images Using Spatial FCM With Level Set Segmentation
}

\author{
B. Sudha, Surjeet Dalal, Kathiravan Srinivasan
}

\begin{abstract}
Glaucoma is a malady of the optic nerve brought about by the expansion in the intraocular weight of the eye. It for the most part influences the optic plate by expanding the cup size. In this proposed method the clinical parameter such as vertical optic cup to disk ratio (CDR) is determined to identify the glaucomatous disease. The segmentation of optic disc (OD) and optic cup in retinal fundus image is an important step in the determination of CDR. Optic Disc is extracted from the fundus image by circular region of interest with Hough transformation. Linear regression fit is used to find the Gold standard value for the experimentally obtained CDR A Bayesian classifier is used to train the classifier set of CDR values obtained. Results produced from the classification obtain a accuracy of $94.28 \%$, sensitivity of $94.38 \%$ and specificity of $94.11 \%$. ROC curve is plotted to study the relation between specificity and sensitivity of the CDR and $G S V$. This proposed approach is robust in segmentation and the region boundaries are precise and is able to yield regions more homogeneous which can be used for objective mass screening of retinal images for early detection of Glaucoma.
\end{abstract}

Key words: Glaucoma, CDR, Spatial Fuzzy clustering, Level set method.

\section{INTRODUCTION}

For the PC supported determination of a few diabetic retinopathies, it is important to assess a few eye fundus picture highlights. In [1-7] another versatile morphological strategy for the programmed discovery of the middle and edge of the optic circle in advanced shading eye fundus pictures. In [8] A deformable-model based methodology is utilized for powerful discovery of optic circle and cup limits The came about cup-to-plate (C/D) proportion indicates great consistency and similarity when contrasted and the outcomes from Heidelberg Retina Tomograph (HRT) under clinical validation. In [9] Automatic optic plate division dependent on area developing system with programmed seed determination is used. In [10] Optic circle and Optic cup division utilizing superpixel order is utilized. In [11-14] for the division of optic plate another all-encompassing LBF dynamic shapes calculation and for optic cup a calculation dependent on SEFCM grouping and morphological activities is presented. In [15] to recognize Glaucoma 13 morphological qualities that characterize mfERG accounts and orders those utilizing an outspread premise capacity

Revised Manuscript Received on April 19, 2019.

B. Sudha, Research Scholar, School of Information Technology and Engineering, VIT, Vellore, Tamilnadu, India.

Dr. Surjeet Dalal, Associate Professor, Dept. of Computer Science and Engineering, SRM University, Haryana, India.

Dr. Kathiravan Srinivasan, Associate Professor, School of Information Technology and Engineering, VIT, Vellore, Tamilnadu, India. system prepared with the Extreme Learning Machine calculation.

\section{SCOPE AND OBJECTIVE}

Some significant changes of the optic plate coming about because of glaucoma are [16] exhuming development limited and summed up diminishing of the optic nerve nearness of indents in the unearthing edge; loss of nerve strands; asymmetry of the uncovering in the two eyes; Cup development, veins blade; profound removal with noticeable scleral gaps; and neuroretinal edge thickness. In touching base at a conclusion, ophthalmologists utilize the purported cup/plate proportion.

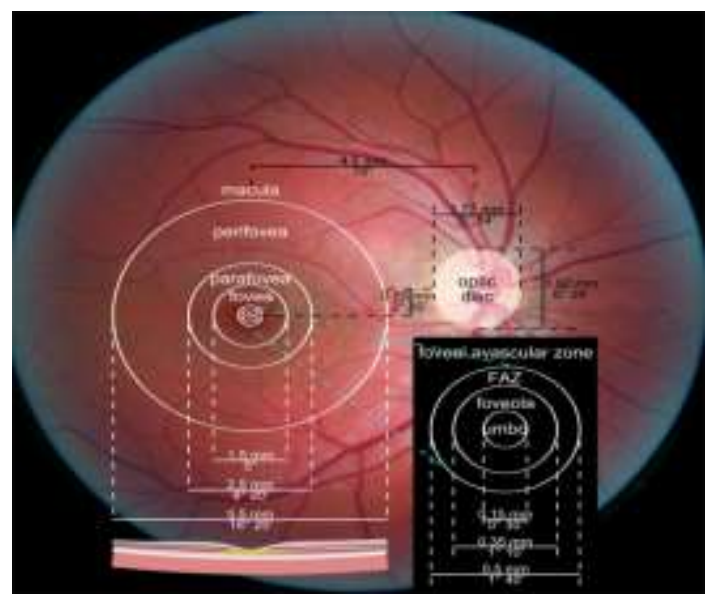

Figure.1 Retinal main features in a typical eye fundus image.

It is simpler for experts to assess initially on intraocular weight utilizing instrument subjectively than to gauge the cup/circle proportion in the fundus pictures. Numerous potential methods have been proposed to identify the CDR esteem. This work presents one such new strategy for the location and characterization of retinal pictures that delineates glaucoma dependent on CDR esteem. The strategy investigates cup and circle extraction absolutely utilizing spatial fluffy grouping method. The methodology depends on the cozy relationship found between the cup width and its development inside the optic plate zone with centrality measures. In this way, It is conceivable utilizing the proposed strategy to order physiologically typical versus suspect unearthings, notwithstanding when they are in their

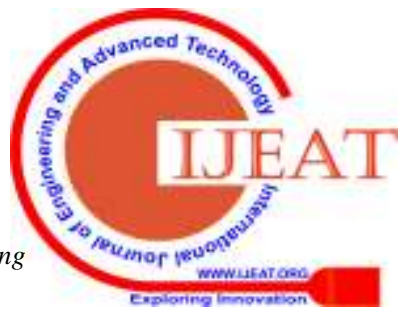


International Conference on Recents Advancements in Engineering and Technology (ICRAET-18) |15th and 16th March 2019|Siddhartha Institute of Technology \& Sciences, Telangana, India.

underlying phases of improvement.

\section{MATERIALS AND METHODS}

\section{Image database}

Our proposed technique was tried on fundus picture society databases of retinal pictures. It incorporates 155 fundus pictures of $720 \times 720$ pixels, caught utilizing a $45^{\circ}$ field-of-see fundus camera.

\section{PROPOSED METHOD}

In this paper, we present a programmed strategy for identifying the optic circle in a shading eye fundus picture. Our methodology depends on cup and circle division process with the accompanying stages as appeared in Fig.2. At first the picture dataset is preprocessed with complexity modification for enlightenment redress by Otsus thresholding strategy. The subsequent stage is the vein division process for evacuating the veins in the fundus picture. The third stage incorporate the optic nerve head standardization for recognizing the careful circle district. The fourth stage incorporate the division of circle area utilizing round district of intrigue based division strategy. At that point the spatial FCM technique is included to fragment the cup district from the circle locale, which is the proceeded with the level, set division procedure to limit the territorial estimation of the portioned cup area. Next the component extraction procedure happens to consider the measurable parameters, which change the cup and circle measurement. At long last these qualities are prepared and group by a Bayesian SVM classifier for examining the exhibition measurements of the proposed design.

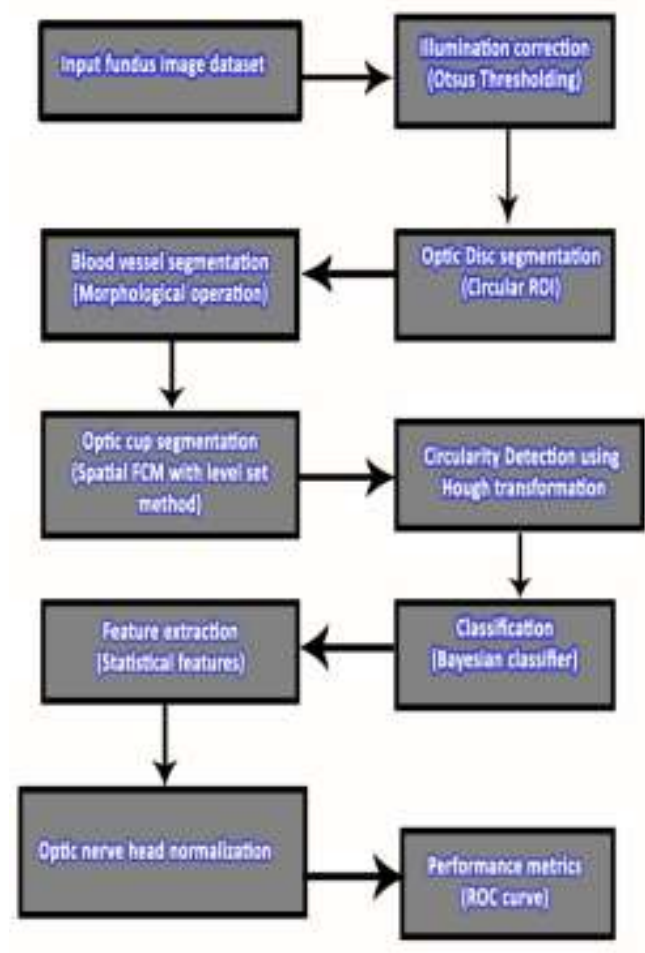

Figure.2 Architecture of the proposed system

\section{Preprocessing:}

The information retinal fundus picture is resized picture as $720 \times 720$ pixels and RGB picture is changed over in to dim level picture. The assessment of the optic plate district is basic to the acknowledgment of glaucomatous harm. An optic plate irregularity is regularly, however not generally, the main indication of glaucomatous harm. In the soonest phases of the infection, plate area harm might be available, while standard mechanized perimetry is still inside typical points of confinement. In light of a five-rule approach the glaucomatous harm can be recognized from the cup and plate district. These principles stand a clear path for the improvement of the proposed approach. The principles are appeared in Table.1.

Table.1: Proposed rules to evaluate optic disc segmentation for glaucoma

\begin{tabular}{|l|l|}
\hline Number & Rule \\
\hline Rule 1 & $\begin{array}{l}\text { Watch the scleral ring to distinguish the } \\
\text { points of confinement of the optic plate } \\
\text { and its size }\end{array}$ \\
\hline Rule 2 & Distinguish the size of the Rim \\
\hline Rule 3 & Inspect the Retinal nerve fibre layer \\
\hline Rule 4 & $\begin{array}{l}\text { Inspect the Region of parapapillary } \\
\text { atrophy }\end{array}$ \\
\hline Rule 5 & $\begin{array}{l}\text { Search for Retinal and optic disc } \\
\text { hemorrhages }\end{array}$ \\
\hline
\end{tabular}

\section{Illumination correction by Otsu's thresholding}

Low and High values for thresholding are obtained from the histogram. In the proposed method the low value is taken as 47 and the high value is taken as129 as the optic disc contrast ranges from 47 to 129 by the measurement process. Pixel intensity based measurement- to find ROI. Optic disk pixel intensity varies generally from130-255 and $1 \mathrm{~mm}=43.5$ pixels $.1 .7 \mathrm{~mm}=77$ pixels. Therefore optic disc radius is calculated as 38 pixels. Then pixel to Distance conversion is carried out to find the centroid of optic disc (ROI). Setting of position constraints (pix1, piy1, pix2, piy2) is done using the centroids 1 and 2 on the disc radius and the disc radius and the distance line is obtained from these position constraints.

\section{Blood vessel segmentation}

To begin with, we play out an unpleasant division of the retinal vascular structure. In light of the underlying pixelwise division continuative strategies guarantee the worldwide network and geography of the vessel tree (19). We consolidated edge-based and layout coordinating procedures to extricate the vessel tree from the fundus pictures. 


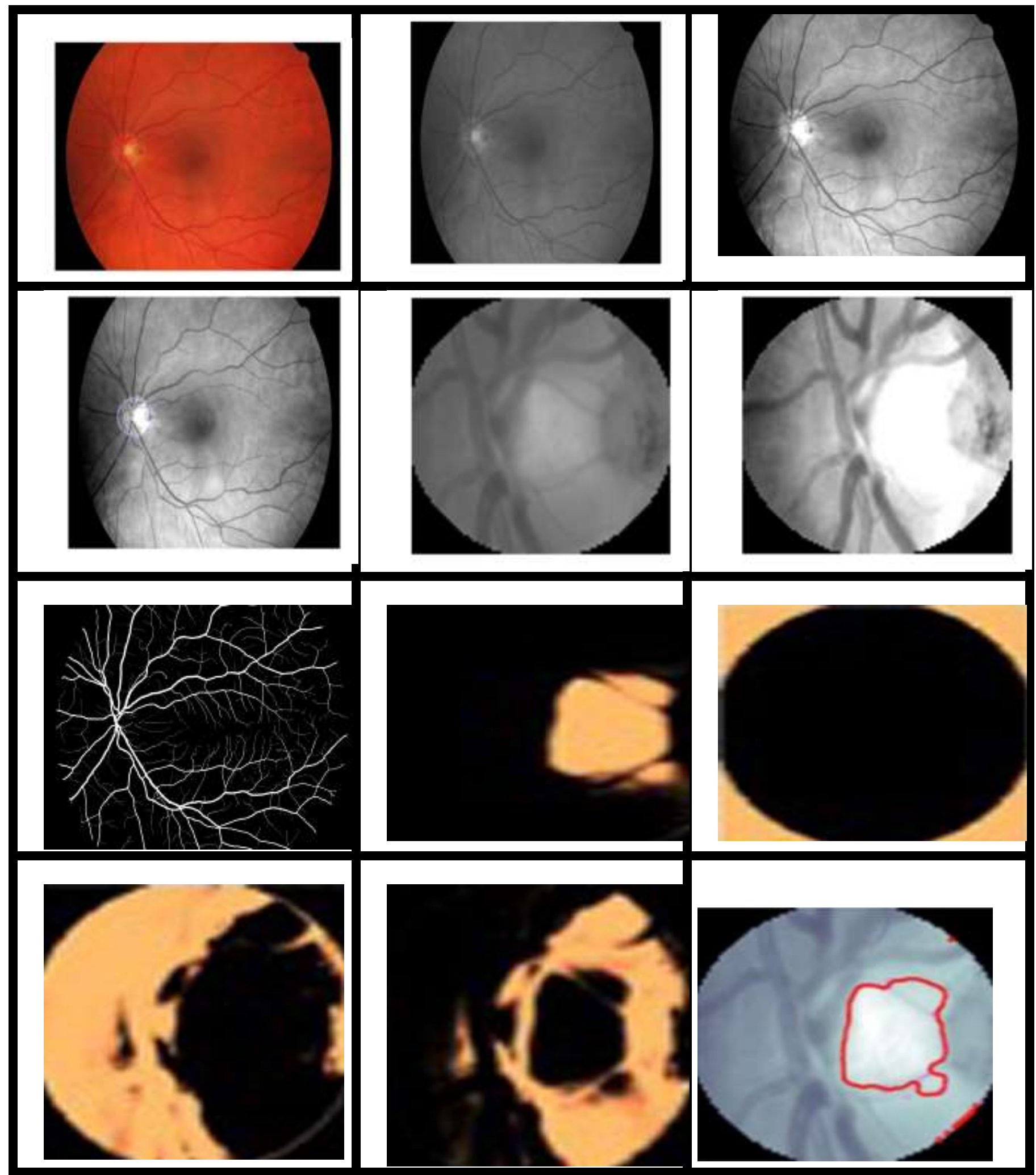

Figure.6.Image processing technique of optic cup and disc extraction (a) Original image; (b) gray scale conversion image; (c) Otsus thresholded image; (d) hough transformed image for circularity retinal rim detection; (e) circular ROI segmentation image on Disc extraction; (f) OHN normalized image; (g) Blood vessel segmentation image; (h) Spatial FCM with level set segmentation on cup extraction image; (i) Spatial FCM with level set segmentation on boundary extraction image; (j) Spatial FCM with level set segmentation on cup extraction image; (k) Spatial FCM with level set segmentation on improper connectivity extraction image; (l) Level set segmentation on boundary trace for cup region.

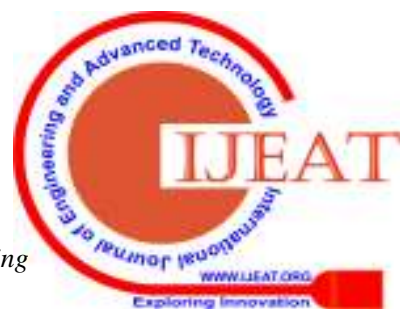


International Conference on Recents Advancements in Engineering and Technology (ICRAET-18) |15th and 16th March 2019|Siddhartha Institute of Technology \& Sciences, Telangana, India.

\section{Optic nerve head normalization}

As known from face recognition (21), the proposed appearance-based strategy requires at any rate harsh guide correspondences toward have the option to pick up a sensible execution. Thus, we standardize the edge territory as per the optic nerve head outskirt inside particular scopes of optic nerve head sizes. To begin with, the ONH edge must be resolved. In the writing, a few techniques limit the sectioned $\mathrm{ONH}$ edge to be round or circular utilizing, force suppositions or the union of the vessel tree (24). As we are keen on a roundabout mapping of the $\mathrm{ONH}$ edges, we use the division procedure that decides the round edge form of the $\mathrm{ONH}$ fringe as the principal preparing step: accepting the $\mathrm{ONH}$ as the most splendid spot in the fundus picture, an inside gauge is accomplished by a solid power smoothing and further limit examining.

\section{Division of the optic circle area}

\section{Area of intrigue based roundabout trimming}

The target of the optic plate region division is to restrict the locale of enthusiasm for identifying and portioning the anatomic components that are depicted in the subsequent stages, just as to get around the distance across of the circle to be utilized during the time spent standardization. In this paper we utilize the procedure round Region of intrigue created for optic circle division. This strategy comprises of six stages. The division of the optic circle district is made through the roundabout locale of intrigue, which is to be covered for trimming. At long last, the divided optic plate region is superposed on the ROI picture, while simultaneously focusing the pixels of the foundation (AND) rationale activity. The roundabout ROI picture gained is appeared in Fig.6 (e).

\section{Segmentation of the optic cup region}

\section{SPATIAL FCM WITH LEVEL SET METHOD}

For division of optic cup from the optic circle, new Fuzzy level set calculation is proposed (25). Contrasted and different strategies the new calculation is fundamentally improved in the accompanying perspectives:

The inflatable power would now be able to be gotten from spatial fluffy grouping legitimately. In addition level set advancement is presently adjusted to the separation to the veritable article. When moving toward the item, the level set capacity will naturally back the development off and will turn out to be absolutely free on the term. Since a traditionalist $\lambda$ is embraced here, level set advancement balances out naturally. An extra advantage is the adaptability to pick a relatively huge cycle of advancement $\mathrm{T}$ for vigorous division. The divided cup district is appeared in Fig.6 (j-m).

\section{Scope of measurements}

The performed picture preprocessing accentuates glaucomatous varieties among the pictures and permits a nonexclusive and appearance-based element extraction. Statistical features have been extracted from the images to validate the difference between glaucomatous and healthy images as shown in Table.9. These values can be compared with the obtained CDR values for evaluating the error index ५. A Linear regression fit model is created for the obtained CDR values and the GSV values to find the optimized zone for glaucoma detection. These results are shown in Fig.3 and Fig.4.

CDR $=0.3063+0.00380 A-0.001158$ B $-0.000000 A B$

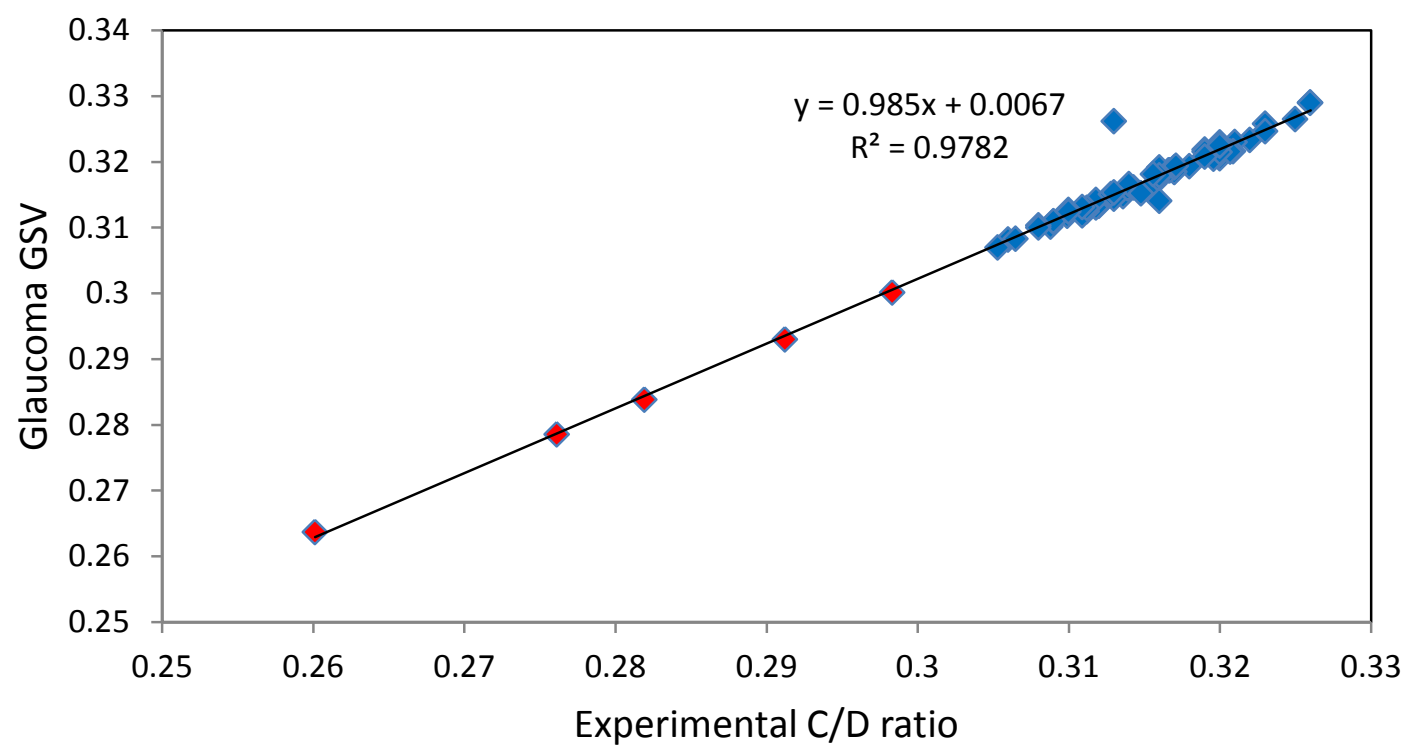

Figure.3 Linear Regression model for Glaucomatous C/D ratio

\footnotetext{
$\mathrm{CDR}=0.4785+0.001077 \mathrm{~A}-\mathbf{0 . 0 0 1 5 3 7} \mathrm{B}+\mathbf{0 . 0 0 0 0 0 7} \mathrm{AB}$
} 


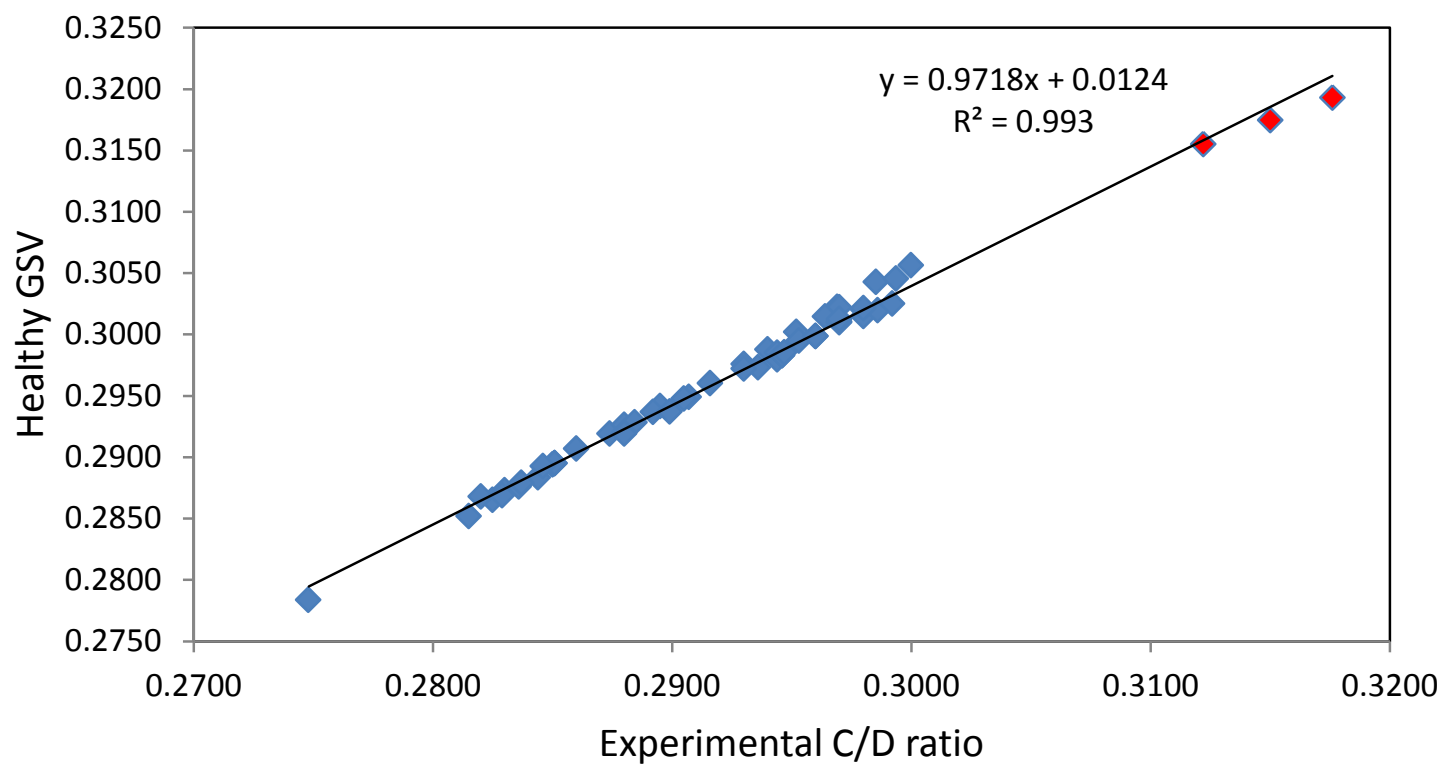

Figure.4 Linear Regression model for Healthy C/D ratio

\section{RESULTS}

155 shading retinal pictures are tried by the proposed glaucoma master framework. Out of 155 shading retinal pictures, 85 are typical and 70 are glaucomatous pictures. As the testing pictures are from various sources, the measures of the pictures are extraordinary. Every one of the pictures are resized to $720 \times 720$ pixel in the event that they are squares; generally, the stature of the picture is resized to 720 pixel while its width is resized by a similar scale. To subjectively assess the proposed calculation, a specialist ophthalmologist has explained all the fundus pictures. We have utilized four execution measures to assess the exhibitions of both circle and cup division techniques. The CDR value evaluated is compared with GSV value from the regression model for the error deviation. These values are shown in Table.6.These values are then trained with a Bayesian classifier for glaucomatous classification. The performance characteristics based on the parameters as shown in Table. 5 is evaluated. ROC curve characteristics are studied for accuracy as shown in Table. 3. Results produced from the ROC characteristics is compared with the various other test results for the consideration of efficient detection of glaucomatous damage. The comparison of various methodologies is shown in Table. 2.

Table.2: Result of some other methods.

\begin{tabular}{|l|l|l|l|}
\hline \multicolumn{1}{|c|}{ S.no } & \multicolumn{1}{|c|}{ Type of analysis } & \multicolumn{1}{c|}{ Sensitivity } & \multicolumn{1}{c|}{ Specificity } \\
\hline 1 & Cup/disc ratio [26, 27, 28, 29] & $60-94 \%$ & $82-94.7 \%$ \\
\hline 2 & $\begin{array}{l}\text { Cup/disc ratio used pairs of stereo retinal } \\
\text { images, [30] }\end{array}$ & $87.5 \%$ & $82 \%$ \\
\hline 3 & Cup/disc ratio and vessel bends [31,32] & $18.6-81.3 \%$ & $45-81.8 \%$ \\
\hline 4 & Cup/disc ratio and ISNT rule [33, 34,35] & $97.6-100 \%$ & $80-99.2 \%$ \\
\hline 5 & Defects of retinal nerve fiber layer [36] & $80-90 \%$ & $54-75 \%$ \\
\hline $\mathbf{6}$ & Proposed method & $\mathbf{9 4 . 3 8 \%}$ & $\mathbf{9 4 . 1 1 \%}$ \\
\hline
\end{tabular}


International Conference on Recents Advancements in Engineering and Technology (ICRAET-18) |15th and 16th March 2019|Siddhartha Institute of Technology \& Sciences, Telangana, India.

Table.3: ROC curve characteristics formulae

\begin{tabular}{|l|l|l|l|l|l|l|}
\hline $\begin{array}{l}\text { PARAMET } \\
\text { ER }\end{array}$ & Sensitivity & Specificity & Accuracy & Precision & Recall & F score \\
\hline FORMULA & $(\mathrm{TP} / \mathrm{TP}+\mathrm{TN}$ & $\mathrm{(TN/TP+T}$ & $(\mathrm{TP}+\mathrm{TN}) /(\mathrm{TP}+\mathrm{F}$ & $(\mathrm{TP} / \mathrm{TP}+\mathrm{FP})$ & $(\mathrm{TP} / \mathrm{TP}+\mathrm{FN}) \mathrm{x}$ & $\begin{array}{l}\text { Precision } \\
\text { recall/pr } \\
\text { ecision }+ \\
\text { recall }\end{array}$ \\
\hline
\end{tabular}

Table.4: Pixel intensity values for contrast adjustment

\begin{tabular}{|l|l|l|l|}
\hline Features & Min & Mean & Max \\
\hline Optic Cup & 23 & 126 & 173 \\
\hline Optic Disc & 57 & 148 & 235 \\
\hline
\end{tabular}

Table.5: Primary conditions of ROC analysis

\begin{tabular}{|l|l|}
\hline ROC & Description \\
\hline True Positive & Image classified as Glaucoma that proved to be Glaucoma \\
\hline True Negative & Image classified as healthy that proved to be healthy \\
\hline False positive & Image classified as healthy that proved to be Glaucoma \\
\hline False negative & Image classified as Glaucoma that proved to be healthy \\
\hline
\end{tabular}

\section{Validation}

The ROC bend was made with unquestionably positive and certainly negative outcomes; thus the bend indicates just a solitary working point.

Table.6: Values of vertical cup to disc ratio.

\begin{tabular}{|c|c|c|c|}
\hline CUP DIAMETER & DISC DIAMETER & CDR-OBSERVED & CDR-GSV \\
\hline 0.0904 & 0.32 & 0.2826 & 0.289 \\
\hline 0.0391 & 0.2978 & 0.1221 & 0.1388 \\
\hline 0.0728 & 0.3045 & 0.239 & 0.2487 \\
\hline 0.0654 & 0.3124 & 0.2093 & 0.2113 \\
\hline 0.0325 & 0.2874 & 0.1130 & 0.1301 \\
\hline 0.0528 & 0.3214 & 0.1642 & 0.019 \\
\hline 0.0845 & 0.2956 & 0.2858 & 0.302 \\
\hline 0.0785 & 0.3025 & 0.2595 & 0.2717 \\
\hline 0.0524 & 0.32 & 0.1637 & 0.1545 \\
\hline 0.0786 & 0.3156 & 0.2490 & 0.2536 \\
\hline 0.0489 & 0.3290 & 0.1486 & 0.1294 \\
\hline 0.0632 & 0.3127 & 0.2021 & 0.2024 \\
\hline 0.1275 & 0.2532 & 0.5837 & 0.5151 \\
\hline 0.1257 & 0.2532 & 0.4964 & 0.5087 \\
\hline 0.124 & 0.2532 & 0.48 & 0.5027 \\
\hline 0.1320 & 0.2459 & 0.5368 & 0.5413 \\
\hline 0.1452 & 0.2532 & 0.5734 & 0.5778 \\
\hline 0.1526 & 0.2354 & 0.6482 & 0.6292 \\
\hline 0.1238 & 0.2498 & 0.4955 & 0.5068 \\
\hline 0.1574 & 0.2510 & 0.6270 & 0.6241 \\
\hline 0.1126 & 0.2432 & 0.4629 & 0.4764 \\
\hline 0.1475 & 0.2468 & 0.5976 & 0.5950 \\
\hline 0.1328 & 0.2516 & 0.5278 & 0.5361 \\
\hline 0.1358 & 0.2541 & 0.5344 & 0.5432 \\
\hline
\end{tabular}




\section{CONCLUSION}

This paper shows a specialist framework to analyze glaucoma dependent on a novel division strategy to recognize the limits of Disk and Cup area in fundus picture. In light of the exact data about the shapes, various parameters are figured comparing. The proposed master framework identifies the glaucoma as well as arranges the seriousness of the illness dependent on the measurable approval. This model upgrades the cup and plate extraction with a tuned territorial division, which is through the level set technique. The outcomes achieved by the proposed strategy demonstrate that it distinguishes the shape of cup locale with high precision for both ordinary and glaucomatous pictures. Another bit of leeway of the proposed strategy is that it doesn't force any shape imperative on the division result. The technique was effective in 135 pictures out of 155 , accomplishing $94.38 \%$ affectability, $94.11 \%$ explicitness, and $94.28 \%$ worldwide exactness. This demonstrates the strategy is successful, and it could be utilized to grow new medicinal frameworks for the pre-analysis of glaucoma by PC.

Table.7: Results of the proposed method.

\begin{tabular}{|l|l|}
\hline \multicolumn{1}{|c|}{ Diagnosis } & \multicolumn{1}{c|}{ Result } \\
\hline True positive (TP) & 82 \\
\hline True negative (TN) & 65 \\
\hline False positive (FP) & 3 \\
\hline False negative (FN) & 5 \\
\hline Sensitivity & $94.38 \%$ \\
\hline Specificity & $94.11 \%$ \\
\hline Area under the ROC curve & $92.3 \%$ \\
\hline Global accuracy & $94.28 \%$ \\
\hline
\end{tabular}

Table.8: Parameters controlling level set segmentation

\begin{tabular}{|l|l|}
\hline Parameter & \multicolumn{1}{c|}{ Significance } \\
\hline$\sigma$ & $\begin{array}{l}\text { Controlling the spread of Gaussian } \\
\text { smoothing capacity }\end{array}$ \\
\hline $\mathrm{C}$ & $\begin{array}{l}\text { Controlling the slope quality of } \\
\text { introductory level set capacity }\end{array}$ \\
\hline$\varepsilon$ & Regulator for Dirac function $\delta(\varnothing)$ \\
\hline$\mu$ & $\begin{array}{l}\text { Weighting coefficient of the punishment } \\
\text { term } \zeta(\varnothing)\end{array}$ \\
\hline$\lambda$ & $\begin{array}{l}\text { Coefficient of the shape length for } \\
\text { smoothness guideline }\end{array}$ \\
\hline$\nu$ & Artificial balloon force \\
\hline$\tau$ & Time venture of level set advancement \\
\hline$T$ & $\begin{array}{l}\text { Most extreme cycle of level set } \\
\text { development }\end{array}$ \\
\hline
\end{tabular}

Table.9 Range of metrics for healthy and glaucoma images

\begin{tabular}{|l|l|l|l|}
\hline Distributiom & Mean & S.D & $\begin{array}{l}\zeta=\text { Mean- } \\
\text { S.D }\end{array}$ \\
\hline $\begin{array}{l}\text { Normal } \\
\text { images }\end{array}$ & 62.3 & 2.68 & 59.62 \\
\hline $\begin{array}{l}\text { Glaucoma } \\
\text { images }\end{array}$ & 68.2 & 2.87 & 65.33 \\
\hline
\end{tabular}

\section{REFERENCES}

1. Murray Fingeret, O.D, Felipe A. Medeiros, M.D, Remo Susanna, Jr, M.D. and Robert N. Weinreb, M.D, Five rules to evaluate the optic disc and retinal nerve fiber layer for glaucoma, OPTOMETRY, VOLUME 76 / NUMBER 11 / NOVEMBER 2005

2. Pravitra and T. C. Manjunath , Dharmanna Lamani and Chandrappa S, Ranjan Kumar H.S. Different Clinical Parameters to Diagnose Glaucoma Disease: A Review, International Journal of Computer Applications (0975 8887) Volume 116 - No. 23, April 2015

3. Chisako Muramatsu, Toshiaki Nakagawa, Akira Sawada, Yuji Hatanaka, Takeshi Hara, Tetsuya Yamamoto, Hiroshi Fujita, Automated segmentation of optic disc region on retinal fundus photographs: Comparison of contour modeling and pixel classification methods. computer methods and programs in biomedicine 101 (2011) 23-32

4. Noor Elaiza Abdul Khalid, Noorhayati Mohamed Noor, Norharyati Md. Ariff, Fuzzy c-Means (FCM) for Optic Cup and Disc Segmentation with Morphological Operation, Procedia Computer Science 42 (2014) 255 262

5. Keh-Shih Chuang, Hong-Long Tzeng, Sharon Chen, Jay $\mathrm{Wu}$, Tzong-Jer Chen, Fuzzy c-means clustering with spatial information for image segmentation. Computerized Medical Imaging and Graphics 30 (2006) 9-15

6. K.NARASIMHAN, Dr.K.VIJAYAREKHA, AN EFFICIENT AUTOMATED SYSTEM FOR GLAUCOMA DETECTION USING FUNDUS IMAGE. Journal of Theoretical and Applied Information Technology, 15th November 2011. Vol. 33 No.1

7. Daniel Welfer, Jacob Scharcanski, Diane Ruschel Marinho, A morphologic two-stage approach for automated optic disk detection in color eye fundus images. Pattern Recognition Letters 34 (2013) 476-485

8. Juan $\mathrm{Xu}$, Opas Chutatape, Eric Sung, Ce Zheng, Paul Chew Tec Kuan, Optic disk feature extraction via modified deformable model technique for glaucoma analysis. Pattern Recognition 40 (2007) 2063-2076

9. Anushikha Singh, Malay Kishore Dutta \& M.Parthasarathi, Radim Burget \& Kamil Riha, An Efficient Automatic Method of Optic Disc Segmentation using Region Growing Technique in Retinal Images. 014 International Conference on Contemporary Computing and Informatics (IC3I)

10. Jun Cheng, Jiang Liu, Yanwu Xu, Fengshou Yin, Damon Wing Kee Wong, Ngan-Meng Tan, Dacheng Tao, Ching$\mathrm{Yu}$ Cheng, Tin Aung, and Tien Yin Wong, Superpixel Classification Based Optic Disc and Optic

11. Cup Segmentation for Glaucoma Screening, IEEE TRANSACTIONS ON MEDICAL IMAGING, VOL. 32, NO. 6, JUNE 2013

12. Pardha Saradhi Mittapalli, Giri Babu Kande Segmentation of optic disk and optic cup from digital fundus images for the assessment of glaucoma, Biomedical Signal Processing and Control 24 (2016) 3446

13. Gopal Datt Joshi, Jayanthi Sivaswamy, S. R. Krishnadas , Optic Disk and Cup Segmentation From Monocular Color Retinal Images for Glaucoma Assessment. IEEE 
TRANSACTIONS ON MEDICAL IMAGING, VOL. 30, NO. 6, JUNE 2011

14. D.W.K. Wong, J. Liu, J.H. Lim, H. Li, and T.Y. Wong, Automated detection of kinks from blood vessels for optic cup segmentation in retinal images. Proc. of SPIE Vol. $726072601 \mathrm{~J}-1$

15. J. Liu, D. W. K. Wong, J.H. Lim, X. Jia, F. Yin, H. Li, W. Xiong, T. Y. Wong Optic Cup and Disk Extraction from Retinal Fundus Images for Determination of Cupto-Disc Ratio, IEEE 2008, pg. 1828-1832

16. L. Boquete, J.M. Miguel-Jimenez, S. Ortega, J.M. Rodriguez-Ascariz, C. Perez-Rico, R. Blanco, Multifocal electroretinogram diagnosis of glaucoma applying neural networks and structural pattern analysis. Expert Systems with Applications 39 (2012) 234-238

17. Consejo de Salubridad general, Aspectos Generales. Centro Nacional de Excelencia Tecnológica en Salud: Diagnóstico y tratamiento del paciente adulto con glaucoma de ángulo abierto, México Secretaría de Salud, CENETEC, 2009.

18. N. Harizman, C. Oliveira, A. Chiang, C. Tello, M. Marmor, R. Ritch, J. M. Liebmann, The ISNT rule and differentiation of normal from glaucomatous eyes, Arch. Ophthalmol. 124 (11) (2006) 1579-1583.

19. Meier, J., Bock, R., Michelson, G., Nyúl, L.G., Hornegger, J., 2007. Effects of preprocessing eye fundus images on appearance based glaucoma classification. In: 12th International Conference on Computer Analysis of Images and Patterns, CAIP. Lecture Notes in Computer Science (LNCS), vol. 4673/2007, Berlin, pp. 165-173.

20. Niemeijer, M., van Ginneken, B., Abramoff, M.D., 2009b. A linking framework for pixel classification based retinal vessel segmentation. In: Proceedings of SPIE, vol. 7262, p. 726216.

21. Shen, J., Chan, T.F., 2002. Mathematical models for local non texture inpaintings. SIAM J. Appl. Math. 62 (3), 1019-1043.

22. Turk, M., Pentland, A., 1991. Eigenfaces for recognition. J. Cognit. Neurosci. 3 (1), 71-86.

23. Zhu, X., Rangayyan, R., Ells, A., 2009. Detection of the optic nerve head in fundus images of the retina using the hough transform for circles. J. Digit. Imag. <http:// dx.doi.org/10.1007/s10278-009-9189-5>.

24. Xu, J., Chutatape, O., Sung, E., Zheng, C., Kuan, P.C.T., 2007. Optic disk feature extraction via modified deformable model technique for glaucoma analysis. Pattern Recognit. 40 (7), 2063-2076.

25. Youssif, A.A., Ghalwash, A.Z., Ghoneim, A., 2008. Optic disc detection from normalized digital fundus images by means of a vessels' direction matched filter. IEEE Trans. Med. Imag. 27 (1), 11-18.

26. Bing Nan li, Chee kong Chui, Stephen Chang, S.H. Ong, Integrating special fuzzy clustering with level set methods for automated medical image segmentation, Computers in Biology and Medicine 41 (2011) 1-10

27. E.M. Felipe-Riverón, M. del Toro-Cespedes, Measurement of parameters of the optic disk in ophthalmoscopic color images of human retina, 17th Iberoamer- ican Congress on Pattern Recognition (CIARP 2012), Lecture Notes Comput. Sci. LNCS 3287 (2004) 661-668.

28. Liu, D.W.K. Wong, J.H. Lim, H. Li, N.M. Tan, T.Y Wong, ARGALI: an Automatic Cup-to-Disc Ratio Measurement System for Glaucoma Detection and Analysis Framework, SPIE 7260, 72603K-8, 2009.

29. C. Muramatsu, T. Nakagawa, A. Sawada, Y. Hatanaka, T. Yamamoto, H. Fujita, Automated determination of cup-to-disc ratio for classification of glaucoma- tous and normal eyes on stereo retinal fundus images, J. Biomed.
Opt.
16
(9)
(2011)
7 ,

30. A. Abdel-Ghafar, A. Morris, B. Ritchings, C. Wood, Detection and characteriza- tion of the optic disk in glaucoma and diabetic retinopathy. In: Proceedings of the 8th Medical Image Understanding Analysis Conference, pp. 23-24, 2004.

31. Y. Hatanaka, A. Noudo, A. Sawada, T. Hara, T. Yamamoto, H. Fujita, Automated measurement of cup to disc ratio based on line profile analysis in retinal images. In: Proceedings of the 33rd Annual International Conference of the IEEE Engineering in Medicine and Biology Society, IEEE Engineering in Medicine and Biology Society, pp. 3387-3390, 2011

32. G.D. Joshi, J. Sivaswamy, S.R. Krishnadas, Optic disk and cup segmentation from monocular color retinal images for glaucoma assessment, IEEE Trans. Med. Imag. 30 (6) (2011) 1192-1205.

33. J. Liu, D.W.K. Wong, J.H. Lim, H. Li, N.M. Tan, T.Y Wong, Automated detection of kinks from blood vessels for optic cup segmentation in retinal images, SPIE 7260, 2009 (72601J-1-72601J-8)

34. J. Nayak, R. Acharya, Automated diagnosis of glaucoma using digital fundus images, J. Med. Syst. 33 (2009) 337-346.

35. S. Kavitha, K. Duraiswamy, An efficient decision support system for detection of glaucoma in fundus images using ANFIS, Int. J. Adv. Eng. Technol. 6 (1) (2012) 226-240.

36. K. Narasimhan, K. Vijayarekha, An efficient automated system for glaucoma detection using fundus image, J. Theor. Appl. Inf. Technol. 33 (1) (2011) 104-110.

37. Y. Hayashi, C. Muramatsu, A. Sawada, T. Hara, T. Yamamoto, H. Fujita, Glaucoma risk assessment based on clinical data and automated nerve fiber layer defects detection, In: Proceedings of the IEEE Engineering in Medicine and Biology Society, pp. 5963-5966, 2012. 